\title{
Safety and comparative costs of preoperative assessments for cataract surgery: traditional mandatory assessment versus a novel graded assessment system Sécurité et coûts comparatifs des évaluations préopératoires pour les chirurgies de cataracte: l'évaluation obligatoire conventionnelle comparée à un système gradué d'évaluation innovant
}

\author{
André Jastrzebski, MD D - Alex Villafranca, MSc • Subash Sethi, MD • Lorne Bellan, MD • \\ on behalf of the Misericordia Health Centre Cataract Surgery Working Group \\ Received: 6 November 2015/Revised: 3 February 2016/Accepted: 29 February 2016/Published online: 4 March 2016 \\ (C) Canadian Anesthesiologists' Society 2016
}

\begin{abstract}
Purpose We conducted this study to evaluate the safety and costs of traditional mandatory preoperative assessment for cataract surgery patients compared with a novel graded preoperative assessment system.

Methods Patients were recruited at a high-volume surgical centre from May to November 2013. Patients completed a health-related questionnaire which allowed for a graded preoperative assessment of all participants. Based on responses to the questionnaire, patients were classified preoperatively into a) low-risk patients not requiring a preoperative assessment and b) high-risk patients requiring this assessment. Anesthesiologists still assessed all patients immediately before surgery but with staff blinded to preoperative assessment information for low-risk patients. Observed complication rates and costs were compared with those expected in the mandatory assessment system.

Results We examined 3,347 cataract surgeries on 2,766 patients and categorized $59.9 \%$ of patients as low risk. In the graded system cohort, there were no major complications and a low rate of minor complications occurred. Wherever a
\end{abstract}

\footnotetext{
A. Jastrzebski, MD $(\bowtie) \cdot$ L. Bellan, MD

Department of Ophthalmology, University of Manitoba and Misericordia Health Centre, Room M264, 99 Cornish Avenue, Winnipeg, MB R3T 2N2, Canada

e-mail: umjastra@myumanitoba.ca
}

A. Villafranca, MSc $\cdot$ S. Sethi, MD

Department of Anesthesia, University of Manitoba and

Misericordia Health Centre, Winnipeg, MB, Canada complication occurred in a low-risk patient, the anesthesiologist doubted that the preoperative assessment information would have prevented the complication. If implemented, the graded system would save approximately 4,414 preoperative assessments per year in our region, with an associated cost of approximately $\$ 40.00$ per surgery, or $\$ 359,000$ in total. The cost to prevent a single minor complication with the mandatory system was approximately $\$ 8,976$, with a number needed to treat of 223 .

Conclusion The graded system resulted in no major complications and a low rate of minor complications. The information obtained from the mandatory assessment is unlikely to prevent complications. Additionally, the cost effectiveness of the mandatory system was poor. This novel graded preoperative assessment system for cataract surgery patients can save time and resources by eliminating unnecessary patient visits.
Résumé
Objectif Nous avons réalisé cette étude pour évaluer la sécurité et les coûts de l'évaluation préopératoire obligatoire conventionnelle pour les patients de chirurgie de cataracte par rapport à un nouveau système gradué d'évaluation.
Méthode Les patients ont été recrutés dans un centre chirurgical d'envergure entre mai et novembre 2013. Les patients ont répondu à un questionnaire sur leur santé qui a permis de faire une évaluation préopératoire graduée de tous les participants. Selon leurs réponses au questionnaire, les patients ont été classés avant l'opération en deux groupes, soit a) les patients à faible 
risque, ne nécessitant pas d'évaluation préopératoire, et b) les patients à risque élevé, nécessitant cette évaluation. Les anesthésiologistes ont tout de même évalué tous les patients immédiatement avant la chirurgie, mais sans avoir connaissance des informations d'évaluation préopératoire pour les patients à faible risque. Les taux de complications observés et les coûts ont été comparés à ceux anticipés lors de l'utilisation du système d'évaluation obligatoire.

Résultats Nous avons passé en revue 3347 chirurgies de cataracte réalisées chez 2766 patients et catégorisé 59,9\% des patients comme courant un risque faible. Dans la cohorte du système gradué, aucune complication majeure n'a été observée, et un faible taux de complications mineures sont survenues. Dans tous les cas où une complication est survenue chez un patient à faible risque, l'anesthésiologiste a estimé que les informations de l'évaluation préopératoire n'auraient pas pu prévenir cette complication. S'il était mis en ouvre, le système gradué permettrait d'épargner environ 4414 évaluations préopératoires par année dans notre région, soit un coût associé d'environ 40 \$ par chirurgie, ou 359000 \$au total. Le coût pour prévenir une seule complication mineure avec le système obligatoire était d'environ 8976 \$, le nombre devant être traité atteignant 223.

Conclusion Le système gradué n'a entraîné aucune complication majeure et un faible taux de complications mineures. Les informations obtenues lors de l'évaluation obligatoire ne peuvent probablement pas prévenir les complications. De plus, la rentabilité du système obligatoire était mauvaise. Ce nouveau système d'évaluation préopératoire gradué pour les patients de chirurgie de cataracte peut épargner temps et ressources en éliminant les visites inutiles de patients.

Cataracts remain the leading cause of preventable blindness worldwide, with the World Health Organization estimating that they cause almost $50 \%$ of worldwide blindness. ${ }^{1-3}$ In the developed world, cataract surgery is one of the most commonly performed operations, with nearly two million procedures performed annually. ${ }^{1,4}$ The United States government spends over $\$ 3$ billion annually on cataract surgery through their Medicare program alone. ${ }^{1,5}$ This cost burden is anticipated only to increase as the rate at which cataract surgery is being performed in the developed world increases. $^{6,7}$

Costs associated with cataract surgery can be categorized as those directly attributable to the procedure and those involving preoperative patient assessment, such as laboratory tests and preoperative history and physical examinations (H\&P). Elimination of preoperative laboratory and diagnostic testing before cataract surgery has been shown to be safe. ${ }^{4-13}$ Nevertheless, recent data suggest marked variability in testing requirements between centres, and many unnecessary tests are still being performed. $^{14,15}$ Additionally, many centres have entirely eliminated preoperative assessment before cataract surgery, either for select patients or for this patient population as a whole. Furthermore, centres still conducting preoperative assessments may feel pressure to eliminate them based on historically low complication rates ${ }^{4,5,10,16-18}$ and the large volume of pending cases. Even so, the evidence supporting elimination of assessment is anecdotal, and primary care H\&Ps remain the standard of care in most areas. ${ }^{13}$ At the time we commenced this study, all patients presenting for cataract surgery in our region required a preoperative assessment to be carried out by a primary care practitioner before surgery.

Before we can recommend the reduction or elimination of preoperative assessments, we must assess the safety and comparative costs of introducing these measures. Therefore, the purpose of this study was to evaluate the safety and comparative costs of the traditional mandatory preoperative assessment system (mandatory system) vs a novel graded preoperative assessment system (graded system).

\section{Patients and methods}

Study design

Following approval from the Research Ethics Board of the University of Manitoba and Misericordia Health Centre in March 2013, patient recruitment occurred at Misericordia Health Centre from May - November 2013. Misericordia Health Centre, a single high-volume surgical centre performing nearly 10,000 cases annually, is the major site for cataract surgery in the region with a catchment area of over one million people from both urban and rural settings. At study initiation, all patients undergoing cataract surgery were required to have an $H \& P$ performed by a primary care practitioner. This practice remained the standard during the course of this study.

We used a prospective counterfactual evaluation design for this study. This involved implementing a graded preoperative assessment system for a single sample of consenting patients, observing the perioperative complication rates and costs of the graded system, and then comparing these observations with the expected outcomes and known costs of the mandatory system (the counterfactual). Therefore, costs and complications in the graded system were known, costs in the mandatory system were known, and complications in the mandatory system were conservatively estimated. 
We developed our questionnaire using information from the literature on complications following cataract surgery, ${ }^{4,16,17}$ with refinement based on consensus from members of the departments of anesthesia and ophthalmology. The quantitative readability of the questionnaire was written at a fifth grade reading level (Fry formula), which is consistent with the healthcare literacy recommendations. In order to be included in this study, participants were required to complete the questionnaire in its entirety. We allowed accompanying family members to help complete the questionnaire. Patients could also ask the research assistant for clarification regarding the questions, as required. Patients were allowed up to $30 \mathrm{~min}$ to complete the questionnaire.

A minimum sample size of 3,200 patients was required to achieve a margin of error $\leq 1 \%$ for all complication rates, assuming a range of possible incidences of 0.1 $10 \% .^{16,17}$ This sample size was also required to achieve an upper confidence limit of no greater than $0.1 \%$, assuming a point estimate of $0 \%$.

\section{Study procedure}

Patient recruitment occurred upon arrival for surgery following a preoperative $H \& P$ performed in the previous six months by a primary care practitioner. The graded system involved classifying consenting patients preoperatively based on their responses to a novel patientcompleted questionnaire. This classification included a) low-risk patients ready for surgery without a preoperative $\mathrm{H} \& \mathrm{P}$ and $\mathrm{b}$ ) high-risk patients requiring this assessment. The questionnaire screened for the presence of numerous preoperative comorbidities, including cardiovascular, respiratory, and renal issues. In addition, body mass index was obtained. Patients were classified as high risk if any high-risk characteristics were present or if their body mass index was $>40$. Table 1 lists the questions that were germane to the classification of patients as high risk and is displayed as it was given to participants.

In low-risk patients, operating room (OR) staff still performed their routine preoperative assessment before entering the OR. We also permitted the anesthesia staff to use an online database to review a list of all prescribed medication for all cases. Nevertheless, we blinded anesthesia staff to all previously performed H\&P and laboratory data until case completion. This allowed us to implement the graded system as well as to assess the importance of withheld information postoperatively. Anesthesia personnel were permitted to unblind themselves if they needed access to the withheld information either to start the procedure safely or to continue the case. Patients classified as high risk had their case proceed as normal with all preoperative assessment information available.
After the case, the anesthesia staff completed an outcome analysis form recording intraoperative or postoperative nonocular complications. Anesthesia staff followed participants until their discharge from the surgical centre. We defined major complications as any unplanned escalation of care or clinical diagnosis of death, cardiac arrest, myocardial infarction, respiratory arrest, coma, stroke, adverse medication reaction, or injury due to fall. Minor complications were defined as less severe events during or after surgery that required the attention of anesthesia staff.

If the patient was low risk, anesthesia personnel were unblinded after the surgery to review the withheld information and to assess whether, and how, it would have altered the care provided. Completing outcome sheets on all patients allowed us to make appropriate inferences regarding the two counterfactuals in our design. The Figure provides a schematic breakdown of this study procedure.

\section{Data analysis}

We used a multi-component economic analysis, including the number of patient visits saved for our study sample and for the region, the raw changes in cost for the sample and for the region, an estimation of comparative costs and number needed to treat (NNT) for the mandatory system, and a cost analysis of missing information. In this case, NNT represents the number of H\&Ps required to prevent a single complication.

Preoperative history and physical examination visits saved

We identified the number of individuals qualifying to skip the H\&P. When OR staff were prematurely unblinded to a low-risk preoperative assessment, we did not count the visit as being saved. If an individual qualifying to skip the H\&P had multiple surgeries, we assumed that only one H\&P was saved for this patient. This assumption is defensible, as the surgeries occurred in close proximity within the data collection period. The probability of a patient requiring separate H\&P visits was therefore low. We calculated the number of saved visits as:

$\mathrm{N}_{\text {saved }}=\mathrm{N} \cdot$ Rate of repeat surgeries

Rate of low-risk patients

We then calculated the proportion of saved H\&P visits as:

Percent $_{\text {saved }}=\left(\mathrm{N}_{\text {saved }} / \mathrm{N}\right) \cdot 100$

Ninety-five percent confidence limits for percent ${ }_{\text {saved }}$ were calculated using the binomial proportion method (Clopper-Pearson) and multiplied by the number of unique visits to back-calculate the confidence limits for $\mathrm{N}_{\text {saved. }}$. 
Table 1 List of key questions defining high-risk patients

\begin{tabular}{|c|c|c|c|c|c|}
\hline 1. What is your current a) height: & t & inch & b) weight: _ $\square$ Kilos & & \\
\hline & Yes & No & & Yes & No \\
\hline 2. In the last 6 months have you: & & & 4. Do you use home oxygen? & & \\
\hline a) Had any angina or chest pain? & & & $\begin{array}{l}\text { 5. Do you have a sleep apnea } \\
\text { machine? }\end{array}$ & & \\
\hline b) Had a heart attack? & & & 6. Do you have a pacemaker? & & \\
\hline 3. In the last 6 months have you gone to & & & 7. Do you have a heart defibrillator? & & \\
\hline the emergency room or been admitted & & & 8. Do you take insulin? & & \\
\hline for: & & & 9. Are you on dialysis? & & \\
\hline a) Your heart? & & & 10. Are you hemiplegic or paraplegic? & & \\
\hline b) Shortness of breath? & & & 11. Does climbing 1 flight of stairs or & & \\
\hline c) A stroke? & & & $\begin{array}{l}\text { walking } 1 \text { city block make you short } \\
\text { of breath? }\end{array}$ & & \\
\hline d) Heart failure? & & & 12. Do you have trouble lying flat (1 & & \\
\hline e) Seizure or blackouts? & & & pillow) for $30 \mathrm{~min}$ ? & & \\
\hline
\end{tabular}

In Manitoba, the fee for a primary care $\mathrm{H} \& \mathrm{P}$ visit depends on the age of the patient: age $<65=\$ 72.00$; age $65-69=\$ 77.65$; and age $>70=\$ 85.90$. To facilitate the calculation of fees paid to primary care practitioners, we calculated both the overall rate of saved visits and the rates for each of the individual age groups, including the confidence limits.

The number of visits saved for the region in a given year was more pertinent than the number of visits saved in the sample. To calculate this savings, we first acquired the total number of cases performed in the region (Misericordia Health Centre) from April 1, 2012 - March 31, 2013 and again eliminated repeat surgeries from these numbers. We assumed that the rate of repeat surgeries in the sample was the best estimate for the rate in the region, as the latter information was not available. In addition, we needed to assume the proportion of patients in the region that would be eligible to skip the H\&P, and this rate was also derived from the sample. The number of saved visits for the region was calculated as:

$\mathrm{N}_{\text {visitsR }}=\mathrm{N}_{\text {region }} \cdot$ Rate of repeat surgeries $\cdot$ Percent saved

Comparative cost due to saved visits

We considered reimbursement by the provincial payer only for preoperative assessments performed by primary care physicians. As mentioned previously, the fee in Manitoba for a primary care H\&P depends on the age of the patient. Therefore, in order to get overall comparative cost estimates for the sample and for the region, we first calculated the cost for patients in the individual age categories and then totalled these costs.

We acquired a breakdown of the number of cataract surgery patients in the region who fell into each of the three age categories from April 1, 2012 - March 31, 2013. We calculated the cost savings for each age category as the product of the cost of a single $\mathrm{H} \& \mathrm{P}$ visit and the number of visits saved. Confidence intervals (CI) for the comparative costs were extrapolated from the confidence limits of the number of visits saved. For instance, the lower confidence limit of the comparative costs was the product of the cost of a single $H \& P$ visit and the lower confidence limit of the proportion of visits saved for that age category.

We aimed to extrapolate the cost estimates from the sample to the entire region. This was done using the same procedure as above, except replacing the number of visits saved in the sample for each age category with the number of visits saved in the region for each age category. We also wanted to present the comparative cost per case in the region. To do this, we divided the total cost savings for the region by the unadjusted number of cataract procedures for the region.

Cost consequence and comparative cost analysis

We performed cost consequence analysis by making tabular comparisons between the two counterfactuals. For this, we assumed that all complications in the mandatory group would have been prevented using the missing information. We then calculated a cost-effectiveness 
measure that considered only the potential cost savings due to saved H\&P visits. We calculated this as the additional costs due to the mandatory system divided by the number of complications assumed to be prevented with implementation of the mandatory system. The result represented the cost to prevent one additional complication. Separate cost-effectiveness calculations were performed for major and minor complications. Since no major complications were observed, the upper limit of the $95 \%$ CI for the major complications was used in this calculation. Using these same assumptions, the NNT was calculated as the number of H\&Ps performed to prevent a single complication.

Cost analysis of missing information

We performed an additional analysis of the cost of missing information to determine the cost to acquire information presumed to be able to prevent complications. This analysis involved two of the authors (A.J. and S.S.) conducting a retrospective chart review. They reviewed all cases where the patient was in the low-risk group, a complication occurred, and anesthesia staff indicated that information present in the preoperative assessment, but not in the questionnaire, may have affected the care provided. We calculated this as the additional costs due to the mandatory system divided by the number of missing pieces of information that were thought to be able to prevent a complication in a low-risk patient.

\section{Results}

Over the course of this study, 3,347 cataract surgery cases were included with 2,766 unique patients. The difference represents the proportion of patients returning for cataract surgery on a second eye (17.4\%). Of the included patients, $1,656(59.9 \%)$ were identified as low risk and had their preoperative data withheld based on their questionnaire responses, with remaining patients classified as high risk. Relevant health demographics that classified patients as high risk are summarized in Table 2. The overall rate of minor anesthesia-related complications in this study was $0.78 \%$ (95\% CI, 0.51 to 1.10 ). No major complications occurred during this study $(0 \% ; 95 \% \mathrm{CI}, 0$ to 0.12$)$. There were 8,893 cataract procedures for the region during the study period (age $<65, n=1,975$; age 65-69, $n=1,453$; age $\geq 70, n=5,465)$.

Table 2 High-risk patient demographics

\begin{tabular}{|c|c|c|c|}
\hline Question & $\begin{array}{l}\text { Fq of positive } \\
\text { responses }\end{array}$ & $\begin{array}{l}\text { Proportion of total } \\
\text { surgeries }(n=3,347) \\
\%(95 \% \mathrm{CI})\end{array}$ & $\begin{array}{l}\text { Proportion of surgeries } \\
\text { on high-risk patients } \\
(n=1,906) \\
\%(95 \% \text { CI })\end{array}$ \\
\hline $\mathrm{BMI}>40$ & 9 & $0.3 \%(0.1$ to 0.5$)$ & $0.5 \%(0.2$ to 0.9$)$ \\
\hline Angina/chest pain (within 6 months) & 141 & $4.2 \%(3.6$ to 4.9$)$ & $7.4 \%(6.3$ to 8.7$)$ \\
\hline Heart attack (within 6 months) & 13 & $0.4 \%(0.2$ to 0.7$)$ & $0.7 \%(0.4$ to 1.2$)$ \\
\hline \multicolumn{4}{|l|}{ ER visit (within 6 months) for: } \\
\hline A heart problem & 63 & $1.9 \%(1.4$ to 2.4$)$ & $3.3 \%(2.5$ to 4.2$)$ \\
\hline Shortness of breath & 94 & $2.8 \%(2.3$ to 3.4$)$ & $4.9 \%(4.0$ to 6.0$)$ \\
\hline Stroke & 13 & $0.4 \%(0.2$ to 0.7$)$ & $0.7 \%(0.4$ to 1.2$)$ \\
\hline Heart failure & 9 & $0.3 \%(0.1$ to 0.5$)$ & $0.5 \%(0.2$ to 0.9$)$ \\
\hline Seizure or blackout & 15 & $0.4 \%(0.3$ to 0.7$)$ & $0.8 \%(0.4$ to 1.3$)$ \\
\hline Use of home oxygen & 37 & $1.1 \%(0.8$ to 1.5$)$ & $1.9 \%(1.4$ to 2.7$)$ \\
\hline Owning a prescribed sleep apnea machine & 137 & $4.1 \%(3.4$ to 4.8$)$ & $7.2 \%(6.1$ to 8.4$)$ \\
\hline Pacemaker & 80 & $2.4 \%(1.9$ to 3.0$)$ & $4.2 \%(3.3$ to 5.2$)$ \\
\hline Defibrillator & 25 & $0.7 \%(0.5$ to 1.1$)$ & $1.3 \%(0.9$ to 1.9$)$ \\
\hline Insulin use & 202 & $6.0 \%(5.3$ to 6.9$)$ & $10.6 \%(9.3$ to 12.1$)$ \\
\hline On dialysis & 15 & $0.4 \%(0.3$ to 0.7$)$ & $0.8 \%(0.4$ to 1.3$)$ \\
\hline Hemiplegic/Paraplegic & 7 & $0.2 \%(0.1$ to 0.4$)$ & $0.4 \%(0.1$ to 0.8$)$ \\
\hline $\begin{array}{l}\text { Shortness of breath on exertion } \\
\text { ( } 1 \text { city block or } 1 \text { flight of stairs) }\end{array}$ & 703 & $21.0 \%$ (19.6 to 22.4$)$ & $36.9 \%(34.7$ to 39.1$)$ \\
\hline Inability to lie flat for $30 \mathrm{~min}$ & 343 & $10.2 \%(9.2$ to 11.3$)$ & $18.0 \%(16.3$ to 19.8$)$ \\
\hline
\end{tabular}

$\mathrm{BMI}=$ body mass index $; \mathrm{CI}=$ confidence interval $\mathrm{Fq}=$ frequency $; \mathrm{ER}=$ emergency room 
Preoperative history and physical examination visits saved

In the sample, our graded system would have saved 1,656 H\&P visits (95\% CI, 1,604 to 1,706). This represented $59.9 \%$ of the study patients (95\% CI, 58.0 to 61.7$)$. This likely would have translated to 4,414 (95\% CI, 4,182 to $4,637) \mathrm{H} \& \mathrm{P}$ visits saved for the region in one year.

\section{Comparative costs due to saved visits}

We calculate a theoretical savings of $\$ 134,647$ (95\% CI, 85,398 to 141,187 ) in the sample due to implementation of the graded system, which represents reimbursement to physicians for performing H\&Ps on all low-risk patients. This would translate to a cost of approximately $\$ 359,000$ (95\% CI, 340,000 to 376,000) for the region over the course of one year. This equates to a theoretical savings of approximately $\$ 40$ per surgery (95\% CI, 38 to 42 ).

Cost consequences and comparative cost analyses

The distribution of minor complications across counterfactuals is shown in Table 3. While these complications do not necessarily indicate clinically meaningful adverse events, they are still surrogate outcomes that suggest a risk for harm. We assumed that all complications in the

low-risk group would have been prevented using the withheld information even though this was unlikely. Despite this conservative assumption, the absolute difference in complication rates between counterfactuals was small $(0.48 \%$; 95\%, CI 0.09 to 0.80$)$, with most observed complications involving treatable hypertension.

Further, assuming all minor complications in the lowrisk group would have been prevented with access to the preoperative assessment, we still calculate a cost of $\$ 8,976$ to prevent a single minor complication. The NNT to prevent a single minor complication is 223. Using the upper limit of the $95 \%$ CI for major complications (although none occurred), we calculate a theoretical cost $>\$ 34,982$ to prevent a single major complication, with an NNT of 870 .

Cost of missing information analysis

There were 62 cases $(1.85 \%$; $95 \% \mathrm{CI}, 1.14$ to 2.36$)$ in the low-risk group where the anesthesiology staff involved in the case indicated that they may have changed the care they provided if they had access to the withheld information prior to the case. In six of these cases, a minor complication occurred. The retrospective review of these six cases showed that the observed complication would not have been preventable using the withheld preoperative assessment information. In five of the six cases, the complication was "intraoperative hypertension", and the missing information was not related to the patients' blood pressure or cardiac health in any of the five cases. In the sixth case, the complication was "excessive patient anxiety during surgery leading to hypertension". This patient had no medical history of anxiety; therefore, this information would not have been indicated in the withheld assessment. Thus, there were no cases $(0 \%$; $95 \%$ CI, 0 to 0.12$)$ where the withheld information would have directly prevented a complication. Using the upper limit of the $95 \% \mathrm{CI}$, the cost associated with acquiring information to prevent a single complication would again be at least $\$ 34,982$.

\section{Discussion}

Our study shows that, in a low-risk population, the entire system of preoperative H\&Ps and associated testing can be skipped while maintaining an extremely low risk of complications. As one of the most commonly performed procedures in modern medicine, cataract surgery is associated with a large cost to the healthcare system. $^{1,3-7,10}$ As such, it becomes imperative that we

Table 3 Breakdown of minor complications across counterfactuals

\begin{tabular}{lll}
\hline Minor complications & $\begin{array}{l}\text { Graded System } \\
\text { Fq }(\% ; 95 \% \mathrm{CI}) *\end{array}$ & $\begin{array}{l}\text { Mandatory System } \\
\text { Fq (\%; } 95 \% \mathrm{CI}) *\end{array}$ \\
\hline Total & $26(0.8 \% ; 95 \% \mathrm{CI}, 0.5$ to 1.1$)$ & $\begin{array}{l}11(0.3 \% ; 95 \% \mathrm{CI}, 0.2 \text { to } 0.6) \\
\text { Hypertension requiring intervention }\end{array}$ \\
Severe bradycardia & $12(0.4 \% ; 0.2$ to 0.6$)$ & $0.1 \% ; 0.04$ to 0.3$)$ \\
New arrhythmia & $1(0.03 \% ; 0.00$ to 0.17$)$ & $2(0.06 \% ; 0.01$ to 0.22$)$ \\
Low $\mathrm{O}_{2}$ saturation $(<90 \%)$ & $6(0.2 \% ; 0.1$ to 0.4$)$ & $1(0.03 \% ; 0.00$ to 0.17$)$ \\
Hypotension $($ MAP decrease $>20 \%)$ & $3(0.1 \% ; 0.01$ to 0.3$)$ & $2(0.06 \% ; 0.01$ to 0.22$)$ \\
Postoperative nausea and vomiting & $3(0.1 \% ; 0.01$ to 0.3$)$ & $1(0.03 \% ; 0.00$ to 0.17$)$
\end{tabular}

*CIs calculated using binomial method (Clopper-Pearson). $\mathrm{CI}=$ confidence interval; $\mathrm{Fq}=$ frequency; MAP = mean arterial pressure 


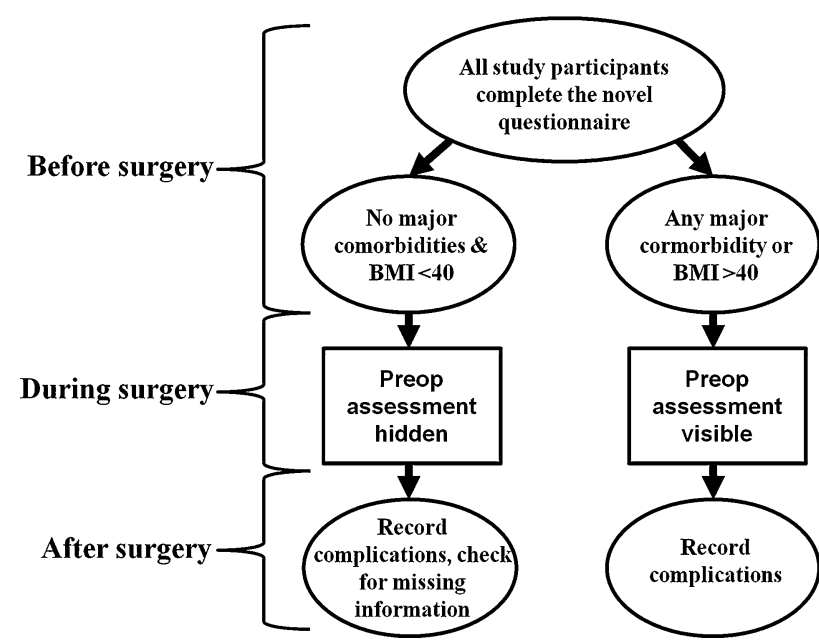

Figure Flow of participants

maximize the cost effectiveness of cataract surgery while maintaining the high levels of safety associated with this procedure. The graded system we have presented is one way to limit unnecessary costs without compromising safety. Nevertheless, the costs associated with preoperative assessment are, more accurately, a surrogate for the time required by family physicians to perform the assessment. We fully expect that primary care physicians would replace these saved visits with other patient encounters, with the hope that they are a more justified use of time and resources.

The graded system is associated with considerable potential cost savings, with a theoretical savings of over $\$ 350,000$ per year at our centre alone. These exact dollar figures are specific to our region; however, the fees associated with preoperative assessment are comparable across Canada. Our analysis also shows that the graded system could be implemented without a clinically meaningful increase in the rate of adverse events. In over 3,300 cataract surgeries, we did not observe a single major complication. We did observe a small number of minor events that were not necessarily clinically meaningful and were present in both high- and low-risk patients. Most of these events involved transient and easily treatable changes in blood pressure. The safety of our approach is further reinforced by the low overall rate of complications in our study group, which does not exceed those presented in other large-scale studies of the systemic risk of cataract surgery. ${ }^{16,17}$

In our counterfactual design, we calculated that the rate of complications would be lower if all patients had a preoperative assessment. This was unsurprising, as we assumed the rate of complications in this group would be zero if implementation did not occur. Despite this very conservative approach, we still show an extremely high cost and burden associated with prevention of both major and minor complications. The reported cost consequences and comparative cost results show the best case scenario for the mandatory system. If we had used the observed rate of major complications instead of the upper limit of the 95\% CI, both the NNT and the cost to prevent a single major complication would have reached positive infinity. Therefore, both the NNT and the comparative costs reported are likely underestimations of the true value and thus underrepresent the benefit of the graded system. By performing a cost of information analysis, we were able to confirm that there were few to no instances where the anesthesia team could have used withheld information to prevent minor complications. This includes misrepresented history from the questionnaire or any data contained within the H\&P.

The major strengths of this study include the use of a rigorous screening questionnaire that was developed using previous research and pathophysiologic rationale and finalized by consensus among representatives from the departments of anesthesia and ophthalmology. Our use of a unique counterfactual design allowed us to observe the implementation of such a system prospectively while retaining the ability to review the preoperative data after completion of surgery. This design also facilitated performing a retrospective review of withheld information and an analysis of the cost of missing information.

Our study is limited somewhat by our lack of a true control group. Ideally, we would have randomly assigned low-risk patients to either standard of care or skipping the H\&P. Nevertheless, the low rate of systemic complications associated with cataract surgery meant that such a prospective study would have been infeasible based on time and cost considerations. This is despite our centre being one of the highest volume cataract sites in Canada. Thus, we used a more powerful single-sample counterfactual design. The weakness of this study design involves the necessity of estimating certain outcomes of interest in one of the counterfactuals (i.e., complication rates with the mandatory system). Even so, we assumed the rate of complications in the low-risk group would have been zero if the withheld information were made available. This conservative estimate avoids overestimation of the safety of the graded system and provides an artificially low benchmark for comparison. The cost of information analysis further reinforces the idea that our design was quite conservative. It shows that additional data acquired during the $\mathrm{H} \& \mathrm{P}$ were unlikely to prevent even minor complications in low-risk patients, while our cost effectiveness and NNT numbers assume that such information would have always prevented the observed complication. 
Notably, the theoretical cost savings presented are likely an underrepresentation of the true savings. We did not include additional areas of savings, such as unnecessary laboratory or diagnostic testing ordered at preoperative visits. Previous studies in the Canadian context have shown that preoperative testing can be safely eliminated, resulting in a meaningful cost savings. A cost savings of approximately $\$ 40$ per case was seen when routine testing was eliminated in cataract surgery patients. ${ }^{4,5,10}$ Our regional guidelines recommend that preoperative testing should be conducted only on cataract surgery patients with medical instability in the preceding six months. Despite these guidelines, many patients still undergo these unnecessary tests.

In our study, the questionnaire was administered on the day of surgery. If implemented in practice, the questionnaire would be completed at the time of surgical booking, often many months before the day of surgery. This time gap could affect the accuracy of the answers provided. Nevertheless, H\&Ps in the current system are often performed (and remain valid) many months before surgery and may be equally flawed in this regard. An additional concern is that we cannot say with certainty that the preoperative assessment itself had no effect on subsequent preoperative care. A patient may have been given a diagnosis at the time of assessment that changed the study group to which they were assigned. Alternatively, interventions could have been initiated due to the questionnaire that may have resulted in better control of an underlying condition at the time of surgery.

In summary, our graded preoperative assessment system is safe and can produce significant potential cost savings over mandatory preoperative H\&Ps by eliminating many unnecessary patient visits. The cost effectiveness of the mandatory system was poor and associated with a high NNT. The withheld information would have rarely prevented even minor complications. If implemented, our graded system could safely decrease the financial burden on the healthcare system and the time burden on patients and physicians. Though the results come from a single centre, this centre serves a large geographical area with a diverse patient population. The specific costs presented are also regionally specific but could easily be calculated for other centres if the local cost of preoperative assessment is known. Future large-scale work could examine the possibility of refining the grading system based on the predictive power of specific questions. In this investigation, there were too few complications to allow such an analysis. Also, a similar graded system could be assessed for other low-risk ocular and non-ocular surgeries performed under topical or regional anesthesia. Our region has adopted the graded system, and we have implemented an ongoing monitoring system to ensure safety of the system in routine practice.
Author contributions: André Jastrzebski, Subash Sethi, Alex Villafranca, and Lorne Bellan contributed to the study design and preparation of the written manuscript. André Jastrzebski, Alex Villafranca, and Lorne Bellan contributed to the data analysis. André Jastrzebski and Subash Sethi contributed to data collection.

Acknowledgments We sincerely thank Rose Djukic from the Centre for Health Innovation and Caroline Dekeyster, Katherine Lane, Gillian Toth, and Barb Ginter-Boyce from the Misericordia Health Centre. We also gratefully acknowledge the day surgery and operating room staff, anesthesiologists, and anesthesia assistants from the Misericordia Health Centre for their assistance in completing our study.

Funding Misericordia Health Centre Foundation and the University of Manitoba Department of Anesthesia Academic Oversight Committee.

Conflicts of interest None declared.

\section{References}

1. Age-Related Eye Disease Study Research Group. Risk factors associated with age-related nuclear and cortical cataract: a casecontrol study in the Age-Related Eye Disease Study, AREDS report No. 5. Ophthalmology 2001; 108: 1400-8.

2. Resnikoff S, Pascolini D, Etya'ale D, et al. Global data on visual impairment in the year 2002. Bull World Health Organ 2004; 82: 844-51.

3. Ryskulova A, Turczyn K, Makuc DM, Cotch ME, Klein RJ, Janiszewski $R$. Self-reported age-related eye diseases and visual impairment in the United States: results of the 2002 national health interview survey. Am J Public Health 2008; 98: 454-61.

4. Schein OD, Katz J, Bass EB, et al. The value of routine preoperative medical testing before cataract surgery. Study of Medical Testing for Cataract Surgery. N Engl J Med 2000; 342: 168-75.

5. Imasogie N, Wong DT, Luk K, Chung F. Elimination of routine testing in patients undergoing cataract surgery allows substantial savings in laboratory costs. Can J Anesth 2003; 50: 246-8.

6. Klein BE, Howard KP, Lee KE, Klein R. Changing incidence of lens extraction over 20 years. Ophthalmology 2014; 121: 5-9.

7. Schein OD, Cassard SD, Tielsch JM, Gower EW. Cataract surgery among Medicare beneficiaries. Ophthalmic Epidemiol 2012; 19: 257-64.

8. Bass EB, Steinberg EP, Luthra R, et al. Do ophthalmologists, anesthesiologists, and internists agree about preoperative testing in healthy patients undergoing cataract surgery? Arch Ophthalmol 1995; 113: 1248-56.

9. Kaplan EB, Sheiner LB, Boekmann AJ, et al. The usefulness of preoperative laboratory testing. JAMA 1985; 253: 3576-81.

10. Keay L, Lindsley K, Tielsch J, Katz, J, Schein O. Routine preoperative testing for cataract surgery. Cochrane Database Syst Rev 2012; 3: CD007293.

11. Schein $O D$. Assessing what we do. The example of preoperative medical testing. Arch Ophthalmol 1996; 114: 1129-31.

12. Walters $G$, McKibbin $M$. The value of pre-operative investigations in local anaesthetic ophthalmic surgery. Eye (Lond) 1997; 11: 847-9.

13. Reeves SW, Tielsch JM, Katz J, Bass EB, Schein OD. A self administered health questionnaire for the preoperative risk 
stratification of patients undergoing cataract surgery. Am J Ophthalmol 2003; 135: 599-606.

14. Chen CL, Lin GA, Bardach NS, et al. Preoperative medical testing in Medicare patients undergoing cataract surgery. N Engl J Med 2015; 372: 1530-8.

15. Kirkham KR, Wijeysundera DN, Pendrith C, et al. Preoperative testing before low-risk surgery. CMAJ 2015; 187: E349-58.

16. Basta B, Gioia L, Gemma M, et al. Systemic adverse events during 2005 phacoemulsifications under monitered anesthesia care. Minerva Anestesiol 2011; 77: 877-83.
17. Moreno-Montanes J, Sabater AL, Barrio-Barrio J, PerezVadivieso JR, Cacho-Asenjo E, Garcia-Granero M. Risk factors and regression calculation of anesthesiologic intervention in topical and intracameral cataract surgery. J Cataract Refract Surg 2012; 38: 2144-53.

18. Rocha G, Turner $C$. Safety of cataract surgery under topical anesthesia with oral sedation without anesthetic monitoring. Can J Ophthalmol 2007; 42: 288-94. 